\section{Matrix and Target Particle-Size Effects on LIBS Analysis of Solls}

Samuel A. Beal, Ashley M. Mossell, and Jay L. Clausen

January 2020

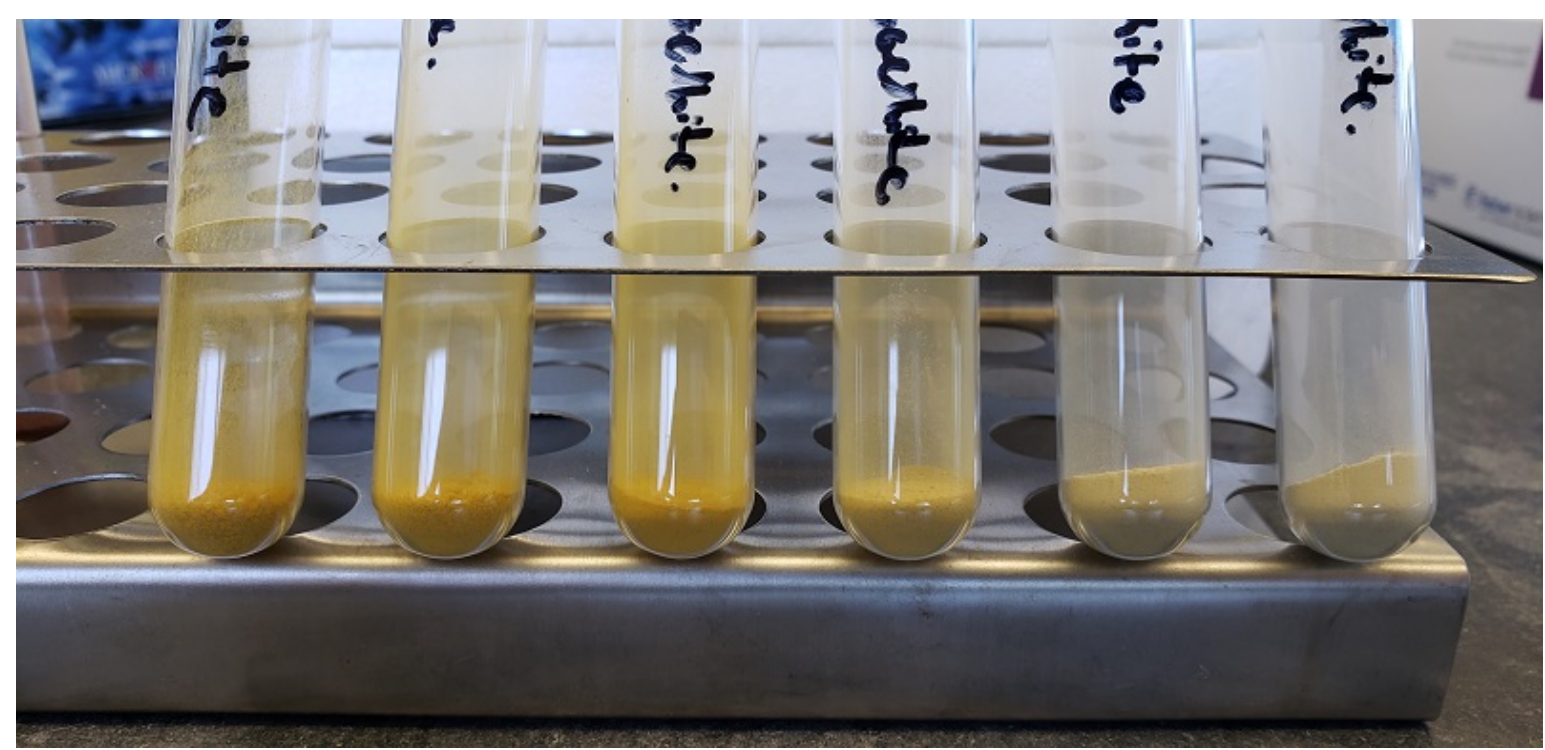


The U.S. Army Engineer Research and Development Center (ERDC) solves the nation's toughest engineering and environmental challenges. ERDC develops innovative solutions in civil and military engineering, geospatial sciences, water resources, and environmental sciences for the Army, the Department of Defense, civilian agencies, and our nation's public good. Find out more at www.erdc.usace.army.mil.

To search for other technical reports published by ERDC, visit the ERDC online library at http://acwc.sdp.sirsi.net/client/default. 


\section{Matrix and Target Particle-Size Effects on LIBS Analysis of Solls}

Samuel A. Beal, Ashley M. Mossell, and Jay L. Clausen

U.S. Army Engineer Research and Development Center (ERDC)

Cold Regions Research and Engineering Laboratory (CRREL)

72 Lyme Road

Hanover, NH 03755-1290

Final Report

Approved for public release; distribution is unlimited.

Prepared for Headquarters, U.S. Army Corps of Engineers

Washington, DC 20314-1000

Under PE 06037348 / Project T15, "Support of US Army Global Military Objectives: LIBS for Military Surveys" 


\section{Abstract}

Laser-induced breakdown spectroscopy (LIBS) is a rapid, low-cost analytical method with potential applications in quantitative analysis of soils for major and trace elements. Here we examined the effects of matrix and target particle sizes on measurements of soil composition by LIBS. The experimental approach involved milling a clean sand matrix to six different particle sizes (medians: 19 to $810 \mu \mathrm{m}$ ) and spiking each with two different iron $(\mathrm{Fe})$ minerals (medians: 1 and $74 \mu \mathrm{m}$ ) to a constant concentration of 5 wt\%. The LIBS intensity of Fe emission lines decreased by $50 \%$ with increasing matrix processing and decreasing matrix particle size, regardless of spike. Conversely, emission lines of the matrix element silicon (Si) increased with decreasing matrix particle size. We hypothesized that this intensity effect was a result of changing surface concentrations, which was also apparent under visual inspection of the samples. Precision was acceptable for the $1 \mu \mathrm{m}$ Fe spike in all matrices but required further puck milling and particle-size reduction for the larger Fe spike and for determining Si content in both spikes and blanks. These results highlight the importance of matching matrix texture between standards and unknowns and of reducing particle size for quantitative LIBS analysis of soil.

DISCLAIMER: The contents of this report are not to be used for advertising, publication, or promotional purposes. Citation of trade names does not constitute an official endorsement or approval of the use of such commercial products. All product names and trademarks cited are the property of their respective owners. The findings of this report are not to be construed as an official Department of the Army position unless so designated by other authorized documents. 


\section{Contents}

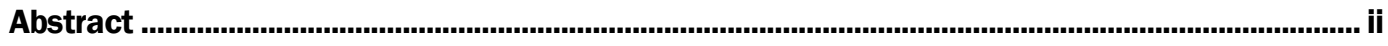

Figures and Tables.......................................................................................................................

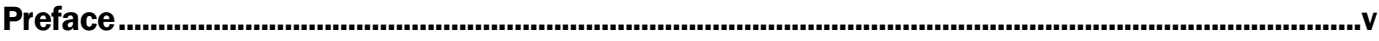

Acronyms and Abbreviations ........................................................................................................

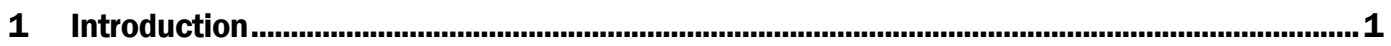

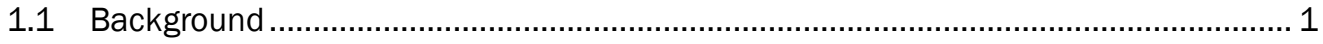

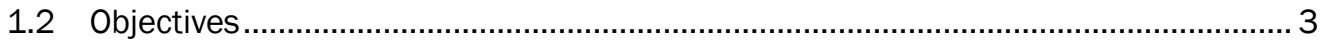

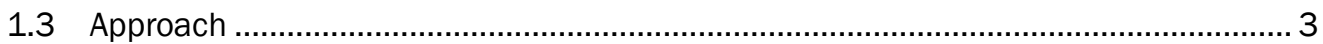

2 Methods .................................................................................................................................. 4

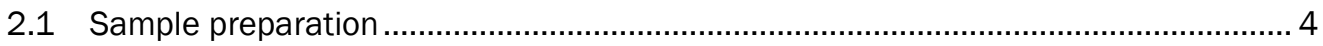

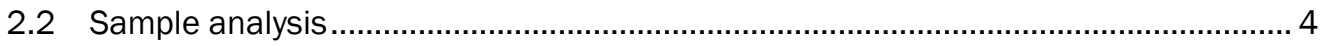

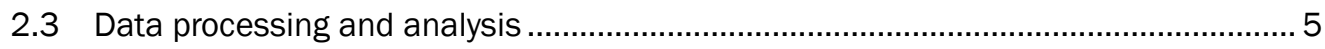

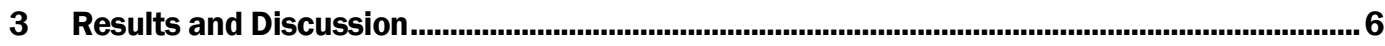

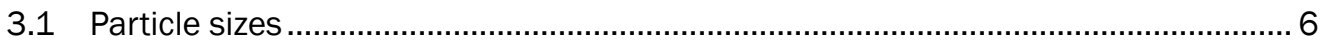

3.2 LIBS spectra and wavelength selection........................................................... 7

3.3 LIBS intensity and precision .................................................................. 10

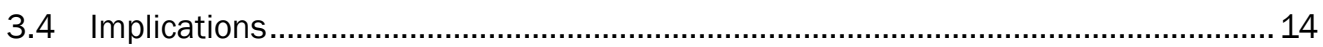

4 Conclusions.................................................................................................................................16

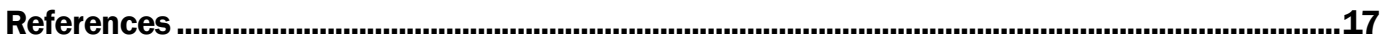

Report Documentation Page 


\section{Figures and Tables}

\section{Figures}

1 Particle-size distributions of iron mineral spikes (top) and Ottawa Sand matrices (bottom)

2 SEM images of the spike materials iron (III) oxide at $870 \times$ magnification (left) and goethite at 8100× magnification (right)

3 Averaged LIBS spectra for blank Ottawa Sand, Ottawa Sand spiked with 5 wt\% goethite, and Ottawa Sand spiked with 5 wt\% iron (III) oxide in each matrix by preparation type

$4 \quad$ LIBS spectra surrounding Fe emission peaks at 373.530 and 372.015 $\mathrm{nm}$. Spectra are the average for each 9-shot repetition and plotted by preparation type and spike ( $5 \mathrm{wt} \%$ goethite and iron (III) oxide)

$5 \quad$ LIBS spectra surrounding an Si emission peak at $288.234 \mathrm{~nm}$. Spectra are the average for each 9-shot repetition and are plotted by preparation type and spike ( $5 \mathrm{wt} \%$ goethite and iron (III) oxide)

6 Boxplots of LIBS intensity and normalized intensity at $373.530 \mathrm{~nm}(\mathrm{Fe})$ and at $288.234 \mathrm{~nm}$ (Si) for blank Ottawa Sand and Ottawa Sand spiked at $5 \mathrm{wt} \%$, by matrix preparation type

$7 \quad$ Relative standard deviations for Fe $(373.530 \mathrm{~nm})$ and Si $(288.234 \mathrm{~nm})$ emission intensities between individual shots within a repetition (intraRSD) and between the six repetitions per sample (inter-RSD). Error bars are \pm 1 standard deviation

$8 \quad \mathrm{Fe}(373.530 \mathrm{~nm})$ and $\mathrm{Si}(288.234 \mathrm{~nm})$ intensity and precision as a function of median matrix particle size. The median particle sizes for the studied goethite and iron (III) oxide are 0.99 and $74 \mu \mathrm{m}$, respectively

9 Images of goethite (left) and iron (III) oxide (right) samples spiked to 5 wt $\%$. In both images, the matrix is raw on the left and increases in level of processing toward the right

\section{Tables}

1 Significant difference matrix of Fe intensities by pairwise t-tests. Goethite $(G)$ and iron (III) oxide (I) with significant differences are indicated by * for $p$-values $<0.05, * *$ for $p<0.01$, and $* * *$ for $p<0.001$

2 Significant difference matrix of $\mathrm{Si}$ intensities by pairwise t-tests. Goethite $(G)$, iron (III) oxide (I), and blank (B) with significant differences are indicated by * for $p$-values $<0.05$, ** for $p<0.01$, and *** for $p<0.001$ 


\section{Preface}

This study was conducted for the U.S. Army Corps of Engineers under PE 06037348 / Project T15, "Support of US Army Global Military Objectives: LIBS for Military Surveys."

The work was performed by the Biogeochemical Sciences Branch of the Research and Engineering Division, ERDC Cold Regions Research and Engineering Laboratory (ERDC-CRREL). At the time of publication, Dr. Justin Berman was Branch Chief, and Mr. J. D. Horne was Division Chief. The Deputy Director of ERDC-CRREL was Mr. David B. Ringelberg, and the Director was Dr. Joseph L. Corriveau.

COL Teresa A. Schlosser was Commander of the ERDC, and Dr. David W. Pittman was the Director. 


\section{Acronyms and Abbreviations}

$\begin{array}{ll}\text { CRREL } & \text { Cold Regions Research and Engineering Laboratory } \\ \text { ERDC } & \text { Engineer Research Development Center } \\ \text { Fe } & \text { Iron } \\ \text { ICP-MS } & \text { Inductively Coupled Plasma Mass Spectrometry } \\ \text { LD-PSA } & \text { Laser Diffraction Particle-Size Analyzer } \\ \text { LIBS } & \text { Laser-Induced Breakdown Spectroscopy } \\ \text { Nd:YAG } & \text { Neodymium-doped Yttrium Aluminum Garnet } \\ \text { OS } & \text { Ottawa Sand } \\ \text { RI } & \text { Refractive Index } \\ \text { RSD } & \text { Relative Standard Deviation } \\ \text { SEM } & \text { Scanning Electron Microscopy } \\ \text { Si } & \text { Silicon }\end{array}$




\section{Introduction}

\subsection{Background}

Laser-induced breakdown spectroscopy (LIBS) is a rapid, low-cost standoff elemental analysis technique with potential application in the quantitative analysis of major and trace elements in soil (Harmon et al. 2013). The laser creates a plasma on the surface of a sample with a spot size typically $10-1000 \mu \mathrm{m}^{*}$ in diameter. Atomic and ionic emission lines in the form of ultraviolet, visible, and near-infrared light are collected by the spectrometer following laser firing. LIBS has successfully been applied to analyzing ores, metals, and alloys, typically with a close (tens of centimeters) standoff distance between the laser/optics and the sample (Fortes et al. 2013). Fewer studies have explored long standoff distances for LIBS, although one study demonstrated its potential capabilities by successfully identifying organic substances up to $30 \mathrm{~m}$ (Lopez-Moreno et al. 2006). The ChemCam instrument on the Mars Curiosity rover uses LIBS to interrogate the composition of rocks and soil at a standoff distance of $7 \mathrm{~m}$ (Cousin et al. 2015).

The occurrence of elements in soils depends in part on the element of interest, mineralogy, soil texture, and organic matter content. The inorganic fraction of soils contains silicate and metal oxide minerals composed of lithogenic elements (e.g., Si, Na, K, Ca, Al, Fe, Mn, Ti, and O) that are structurally bound within mineral crystal lattices. Some clay minerals can also host elements in exchangeable interlayer sites. Anthropogenic-enriched elements (e.g., $\mathrm{Pb}, \mathrm{Cd}, \mathrm{As}, \mathrm{Hg}, \mathrm{Ni}, \mathrm{Zn}, \mathrm{Sn}$, and $\mathrm{Sb}$ ) are typically present in soils adsorbed to lithogenic minerals (especially iron and manganese oxides and [oxy]hydroxides), bound in carbonaceous particles, bound in organic matter, or adsorbed to sulfides (Tessier et al. 1979).

Conventional analytical methods for elemental analysis of soils involves complete digestion or partial extraction of a soil sample, followed by analysis of the liquid digest or extract. Complete digestion requires hydrofluoric acid, typically along with hydrochloric acid and nitric acid, to dissolve

\footnotetext{
* For a full list of the spelled-out forms of the units of measure and chemical elements used in this document, please refer to U.S. Government Publishing Office Style Manual, 31st ed. (Washington, DC: U.S Government Publishing Office, 2016), 248-52, https://www.govinfo.gov/content/pkg/GPO-STYLEMANUAL2016/pdf/GPO-STYLEMANUAL-2016.pdf.
} 
silicate minerals and release structurally bound elements. Partial extraction typically aims to dissolve only elements that are adsorbed to lithogenic minerals, bound in organic matter, bound in carbonaceous particles, or otherwise susceptible to acid-dissolution (i.e., carbonates and, to an extent, iron and manganese oxides). Solid digestions and extractions typically take roughly 1 hour to complete. The liquid digestions and extractions can be analyzed by atomic absorption spectroscopy, inductively coupled plasma optical emission spectroscopy, or inductively coupled plasma mass spectrometry (ICP-MS), which typically take 1-10 minutes per sample. Regardless of the technique, conventional analytical methods typically digest or extract a relatively large ( $250 \mathrm{mg}$ to $10 \mathrm{~g}$ ) soil sample.

A potential challenge of applying LIBS to soils analysis is the relatively smaller mass of material that is ablated by the laser. Laser spot sizes usually vary from 10 to $1000 \mu \mathrm{m}$ but ablate less than $1 \mathrm{mg}$ of material (Harmon et al. 2013). Because the analysis is so rapid ( $<1 \mathrm{~s})$, multiple laser shots can be collected across a surface to address heterogeneity in the sample. However, the particulate nature of soils and their heterogeneity at scales greater than the laser spot size pose a major obstacle in accurate and precise soil elemental analysis.

The particle effect in LIBS analysis of soils was noted as early as 1994 . Wisbrun et al. (1994) found that the intensity of cadmium emission in solution-spiked sand samples increased with the grain size of the sand. While the authors stated several effects of particle size on laser interaction, including crater formation and aerosol generation, they also distinguished between the conventional usage of volume/weight concentration and surface concentration-the latter which varies with the surface areas of the matrix and target contaminant. Eppler et al. (1996) used a solid $\mathrm{BaCO}_{3}$ spike to show the significantly enhanced response of Ba emission in sand compared with finer-grain soil. Alexander et al. (1996) observed similar findings for a number of toxic metals in soil, silt, clay, and kaolin. Krasniker et al. (2001) attributed the increase in $\mathrm{Pb}$ emission with grain size in solution-spiked sand to an increase in the size of the formed crater. Anzano et al. (2006) also used this crater-size effect when analyzing pure $\mathrm{Al}_{2} \mathrm{O}_{3}$ to explain an increase in aluminum intensity with increasing particle size; a minimum threshold particle size of $100 \mu \mathrm{m}$ was needed to provide an accurate measurement using a $20 \mu \mathrm{m}$ LIBS spot size. Conversely, Kim et al. (2013) found slightly greater $\mathrm{Cu}$ and $\mathrm{Zn}$ response for $75 \mu \mathrm{m}$ soil samples compared with $2 \mathrm{~mm}$ soil samples, which they suggest resulted from 
greater laser coupling with the finer soil and greater ablated mass. The dependence of LIBS intensity on particle size has been exploited by VillasBoas et al. (2016) and Goueguel et al. (2019) to determine soil texture instead of soil composition.

\subsection{Objectives}

The primary objective was to examine the relationships between LIBS intensity, LIBS precision, target particle size, and matrix particle size in the analysis of soil samples. Secondary goals were to identify sample preparation and analysis methods for the reproducible analysis of unknown soil samples for potential metal contaminants and for major elemental composition.

\subsection{Approach}

We simulated a particle-contaminated soil using two iron minerals of differing particle size spiked into clean sand that was milled to varying matrix particle-size distributions. Changes in the intensity and precision of iron $(\mathrm{Fe})$ and silicon $(\mathrm{Si})$ LIBS emission signals were studied as the target and matrix particle sizes were varied. 


\section{Methods}

\subsection{Sample preparation}

The matrix for all samples was standard Ottawa Sand (OS; sciencelab.com) that was processed to form six matrix particle-size classes with consistent composition: raw unprocessed OS, alumina mortar and pestle (CoorsTek) handground for 5 minutes, puck mill (Labtech Essa LM2) for 30 seconds, puck mill for 1 minutes, puck mill for 3 minutes, and puck mill for 5 minutes. Each matrix type was spiked with solid iron (III) oxide (Aldrich, $>99.9995 \% \mathrm{Fe}_{2} \mathrm{O}_{3}, 68 \%-72 \% \mathrm{Fe}$ ) and the iron (III) oxyhydroxide mineral goethite (Aldrich, $\alpha-\mathrm{FeO}(\mathrm{OH}), 30 \%-63 \% \mathrm{Fe}$ ) in borosilicate glass test tubes. The samples were stirred and shaken until the sample appeared visually homogeneous. Subsamples for pelletization were made by mixing $400 \mathrm{mg}$ of sample with $50 \mathrm{mg}$ of $\mathrm{KBr}(<250 \mu \mathrm{m})$, loading the sample in a $12 \mathrm{~mm}$ die, and pipetting $60 \mu \mathrm{l}$ of MilliQ Type I water on the pellet surface. The $\mathrm{KBr}$ and water were necessary for pellet cohesion. Pellets were pressed with an applied load of $12,000 \mathrm{lb}(5400 \mathrm{~kg})$ in a Carver pellet press for 10 minutes.

\subsection{Sample analysis}

Pressed pellets were analyzed by LIBS (Applied Spectra J200) under a slow stream of ultrahigh purity argon. On the J200, the laser was a 266 $\mathrm{nm} \mathrm{Nd:YAG},{ }^{*}$ laser power was $100 \%$, spot size was $100 \mu \mathrm{m}$, ablation time was $100 \mathrm{~ms}$, and washout time was o seconds. Six repetitions were collected across the pellet surface with each repetition consisting of a $3 \times 3$ grid pattern, resulting in 54 shots per pellet.

Pellets were also analyzed by scanning electron microscopy (SEM) with energy dispersive $\mathrm{x}$-ray spectroscopy (Phenom Pro X). Pellets were mounted intact and spike material loosely dispersed on adhesive carbon tape. Voltages were $10 \mathrm{kV}$ for imaging and $15 \mathrm{kV}$ for the energy dispersive $\mathrm{x}$-ray spectroscopy.

Samples of each matrix and spike type were measured for particle size on a Horiba LA-960 laser diffraction particle-size analyzer (LD-PSA). One gram of each sample was suspended in $30 \mathrm{ml}$ of sodium hexametaphosphate solution (38 g/L), vortexed and ultrasonicated, and introduced to

\footnotetext{
* Neodymium-doped yttrium aluminum garnet
} 
the LD-PSA with an autosampler. Raw OS was too coarse for slurry analysis, so it was analyzed as a dry sample through a dry sample attachment and flow cell on the LD-PSA. The LD-PSA used Mie theory to calculate spherical particle volume by using the refractive index (RI) of the material (Ottawa Sand RI with imaginary component: 1.450 0.00oi; iron (III) oxide RI with imaginary component: 2.900 o.oooi; goethite RI with imaginary component: 2.394 0.100i).

\subsection{Data processing and analysis}

Raw LIBS data were purged of non-plasma-forming shots by removing data from shots with negligible signal intensity and inaudible plasma events ( 9 of 1188 total shots). Negative signal intensities were converted to o values. Means, standard deviations, and relative standard deviations (mean / standard deviation) were calculated for each repetition from the $3 \times 3$ shot patterns and for each sample from the six repetitions. Both raw intensities and normalized intensities, using the total spectra intensity (187.252 to $1041.799 \mathrm{~nm}$ ), were used for plotting and data analysis. Means were compared by analysis of variance and pairwise t-tests with Benjamini-Hochberg $p$-value correction. All processing and analysis was performed in R 3.4.3 (R Core Team 2019). 


\section{Results and Discussion}

\subsection{Particle sizes}

We varied particle size for both the spiked target iron minerals and the OS quartz-dominated matrix. The iron (III) oxide spike mineral had much larger particles than the goethite spike mineral, with a median particle size of $74 \mu \mathrm{m}$ compared to $0.99 \mu \mathrm{m}$ for the goethite. The particle-size distribution of goethite used in this study (Figure 1) is sharply centered on submicrometer and single micrometer diameters whereas the iron (III) oxide has a slightly bimodal distribution, ranging from 10 to $500 \mu \mathrm{m}$. Figure 2 shows SEM images of both iron minerals. The iron (III) oxide exhibits mainly irregular particles along with typically smaller plated particles. The goethite images show single micrometer-size needles characteristic of this prismatic mineral; however, some of these needles appear to form loosely packed aggregates.

Figure 1. Particle-size distributions of iron mineral spikes (top) and Ottawa Sand matrices (bottom).
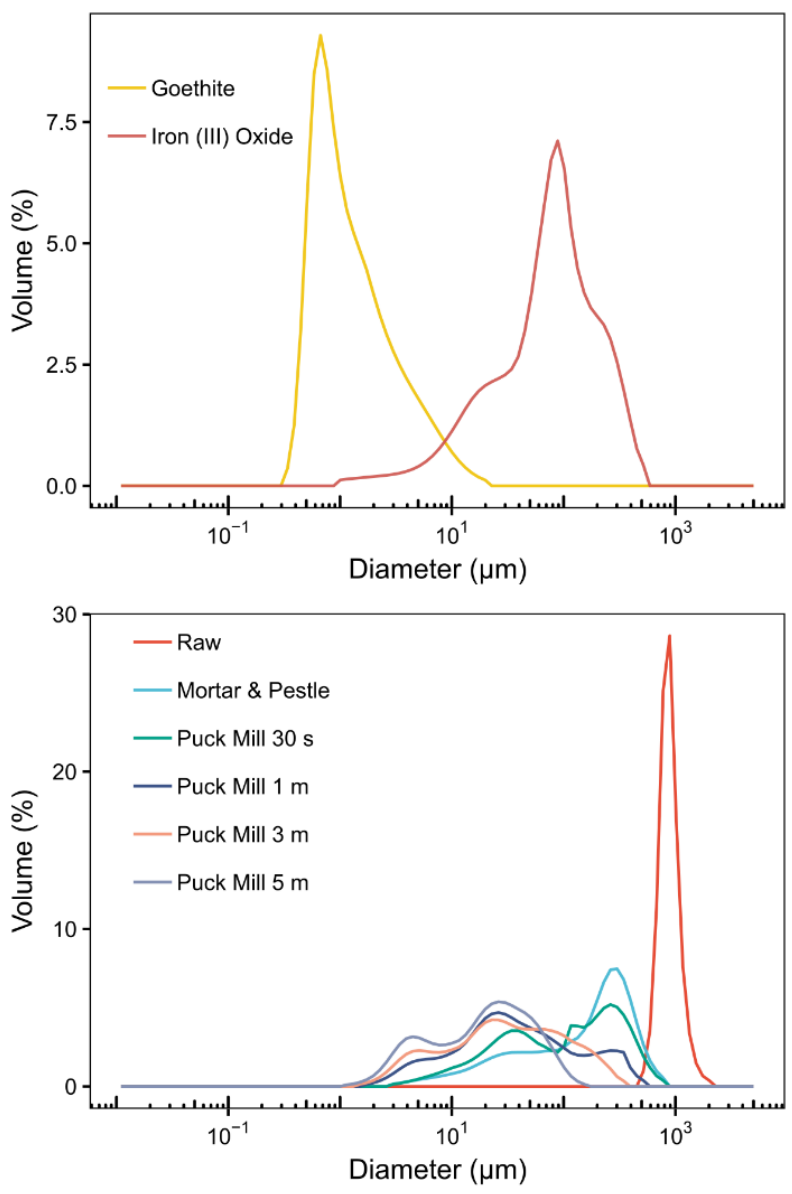
Figure 2. SEM images of the spike materials iron (III) oxide at $870 \times$ magnification (left) and goethite at $8100 \times$ magnification (right).
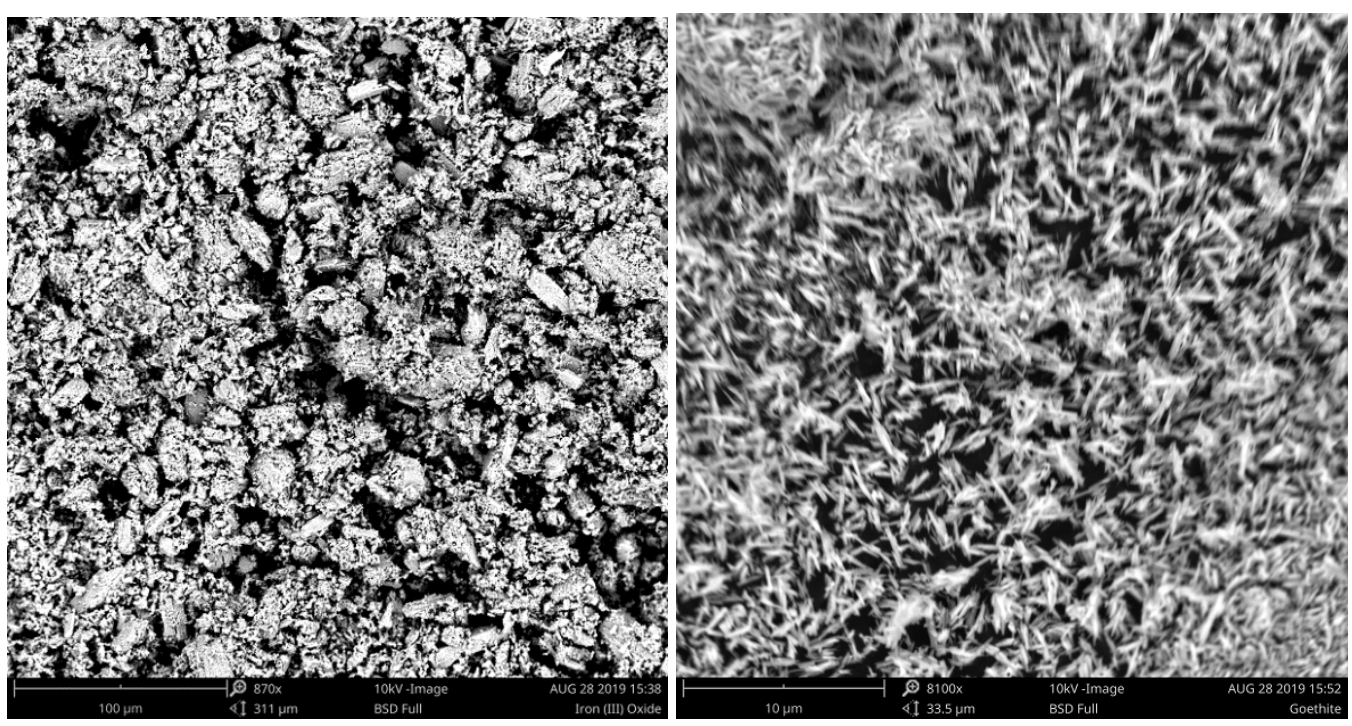

The different milling methods produced OS with different particle-size distributions (Figure 1). Firstly, raw, unprocessed OS has a sharp sand-sized $(\sim 1 \mathrm{~mm})$ distribution and completely lacks particles less than $500 \mu \mathrm{m}$. Grinding with a mortar and pestle reduced median particle size to $170 \mu \mathrm{m}$ but with some particles reduced to $10 \mu \mathrm{m}$ and smaller. The puck mill produced slightly finer particles than the mortar and pestle after 30 seconds (median particle size $103 \mu \mathrm{m}$ ). Prolonged puck milling periods progressively fined and narrowed the particle-size distributions, with median particle sizes of 32,28 , and $19 \mu \mathrm{m}$ for 1 -minute, 3 -minute, and 5 -minute milling periods, respectively.

\subsection{LIBS spectra and wavelength selection}

Figure 3 shows the LIBS spectra from 280 to $900 \mathrm{~nm}$. Emission intensities at wavelengths less than $280 \mathrm{~nm}$ and above $900 \mathrm{~nm}$ were typically near zero. Spectra of blank samples without spiked iron display distinct peaks, likely characteristic of the quartz and silicate mineral matrix composition (i.e., $\mathrm{Si}, \mathrm{O}, \mathrm{Na}, \mathrm{K}, \mathrm{Al}$ ), the $\mathrm{KBr}$ used for pellet formation, and the atmospheric composition (mostly Ar). The major peak between 750 and $800 \mathrm{~nm}$ is likely a multicomponent emission signal from $\mathrm{K}(766 \mathrm{~nm}), \mathrm{O}(777 \mathrm{~nm})$, $\operatorname{Ar}(763 \mathrm{~nm}), \mathrm{N}(746 \mathrm{~nm})$, and $\mathrm{Br}$ (multiple wavelengths between 700 and $800 \mathrm{~nm}$ ) (Kramida et al. 2019). Spectra of the goethite and iron (III) oxide-spiked samples contain a multitude of emission peaks in the ranges of 300 to $450 \mathrm{~nm}$ and 500 to $600 \mathrm{~nm}$. The spectral pattern is similar between the goethite and iron (III) oxide, which reflects the common Fe emission 
lines from both minerals (Kramida et al. 2019). The overall spectral pattern of each sample type (i.e., blank versus spiked) is apparent regardless of the matrix preparation method; however, overall intensities appear to decrease for matrices ground by the puck mill for longer than 30 seconds.

Figure 3. Averaged LIBS spectra for blank Ottawa Sand, Ottawa Sand spiked with 5 wt\% goethite, and Ottawa Sand spiked with 5 wt\% iron (III) oxide in each matrix by preparation type.

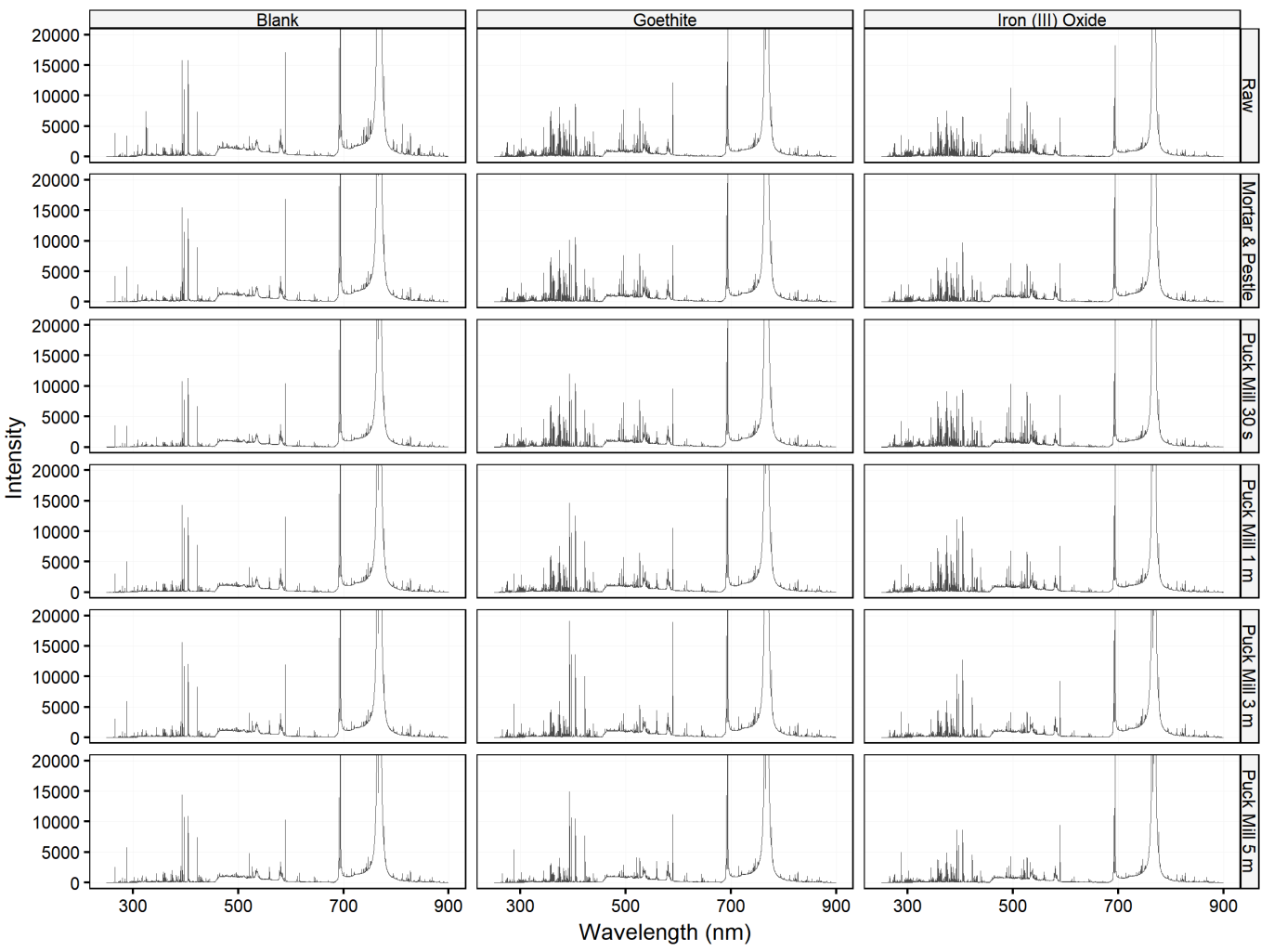

Iron is typically investigated by LIBS through its strong emission line at approximately $372 \mathrm{~nm}$ (Sabsabi et al. 2005). Because of potential wavelength shifts in the LIBS detector, the spectra are investigated between 371 and $374 \mathrm{~nm}$, surrounding its strong emission line at $372 \mathrm{~nm}$ (Figure 4). An Fe peak at $372.015 \mathrm{~nm}$ is apparent in the spectra; however, a comparatively larger peak is apparent nearby at $373.530 \mathrm{~nm}$. These peaks are all consistent with atomic Fe emission lines in the National Institute of Standards and Technology emission database (Kramida et al. 2019). Although less intense, these peaks are also apparent in the blank samples, indicating some baseline Fe in the OS matrix. Overall intensity of this Fe emission cluster appears to decrease in samples puck milled for 3 and 5 minutes compared to less processed samples for both spike materials. Visual con- 
sistency between replicate analyses appears to be high in all goethite samples, regardless of matrix preparation, but is initially low for iron (III) oxide samples in raw and minimally processed matrices. These observed phenomena are addressed quantitatively in section 3.3.

Figure 4. LIBS spectra surrounding Fe emission peaks at 373.530 and $372.015 \mathrm{~nm}$. Spectra are the average for each 9-shot repetition and plotted by preparation type and spike (5 wt\% goethite and iron (III) oxide).

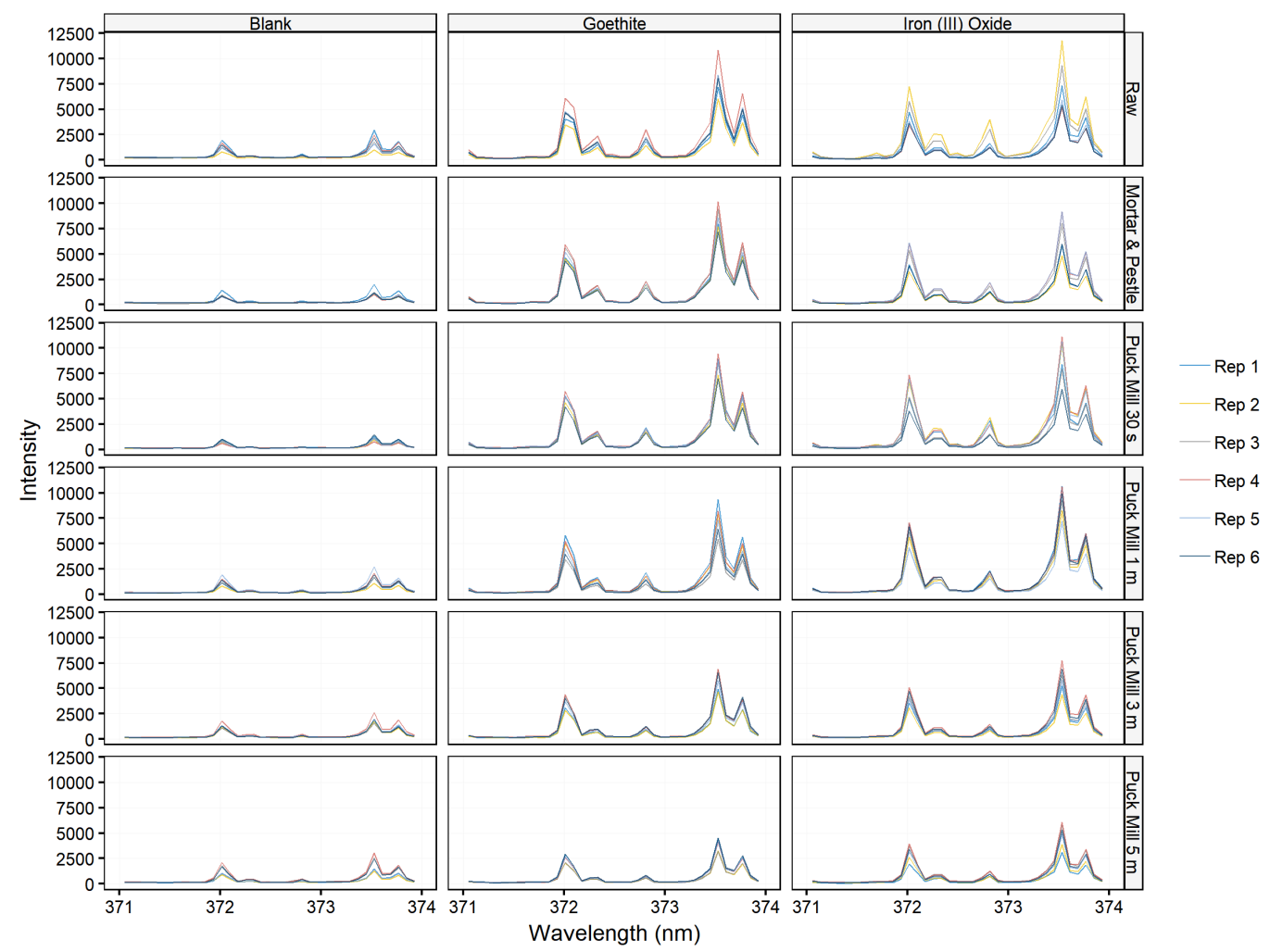

The silicon emission line around $288 \mathrm{~nm}$ is investigated due to its other major emission lines occupying shorter wavelengths $(<280 \mathrm{~nm}$ ) (Kramida et al. 2019) where the instrument is not particularly sensitive. A single peak at $288.234 \mathrm{~nm}$ derived from quartz and silicates in the OS matrix is apparent in all samples (Figure 5). Peak intensity remains relatively stable in the blank and iron (III) oxide samples, regardless of matrix particle size; however, its emission is depressed in goethite samples with raw and minimally processed matrices. Replicate variability appears generally to decrease with decreasing matrix particle size. These observations are discussed in detail in section 3.3. 
Figure 5. LIBS spectra surrounding an Si emission peak at $288.234 \mathrm{~nm}$. Spectra are the average for each 9-shot repetition and are plotted by preparation type and spike ( 5 wt\% goethite and iron (III) oxide).

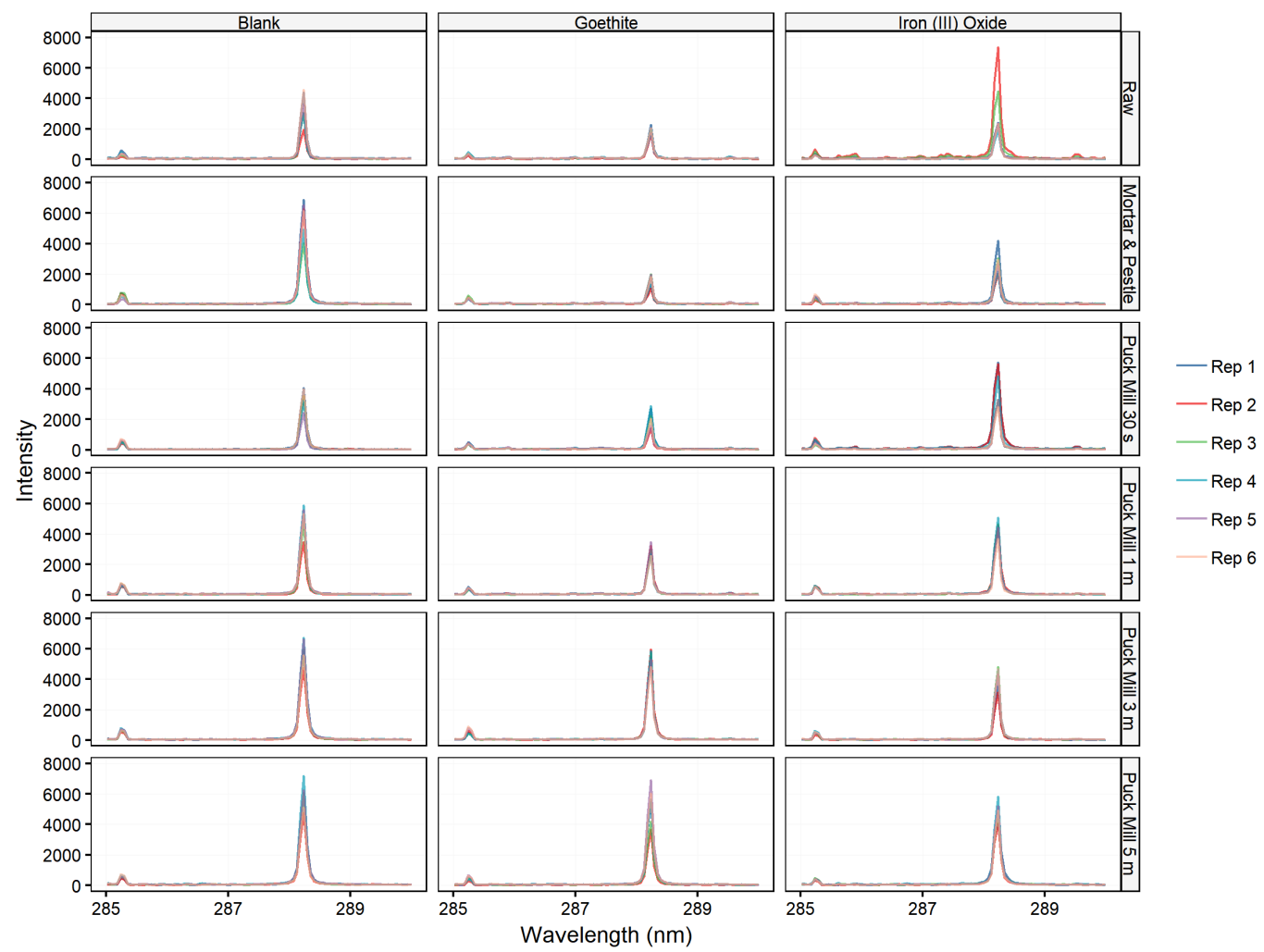

\subsection{LIBS intensity and precision}

Focusing on the selected Fe and Si emission lines, Figure 6 plots LIBS-determined intensities by spike material and matrix preparation as boxplots. Iron intensities are generally greatest for both spike materials in raw OS, OS ground with a mortar and pestle, and 30 seconds and 1 minute milling periods using the puck mill. A decrease in Fe intensities occurs for both spike materials in OS milled for 3 and 5 minutes. These differences are significant using analysis of variance and pairwise t-tests (Table 1) for both spike materials. This same trend is observed in normalized Fe data, but considerably greater variance is present in the normalized data (Figure 6).

Although both spike materials have much greater Fe intensities than the blanks, the iron (III) oxide typically exhibits greater Fe intensity than the goethite (Figure 6), despite the similar mass concentration of $5 \mathrm{wt} \%$. This difference may be attributed to the difference in Fe content between the iron (III) oxide $(68 \%-72 \% \mathrm{Fe})$ and goethite $(30 \%-63 \% \mathrm{Fe})$. 
Figure 6. Boxplots of LIBS intensity and normalized intensity at $373.530 \mathrm{~nm}(\mathrm{Fe})$ and at $288.234 \mathrm{~nm}$ (Si) for blank Ottawa Sand and Ottawa Sand spiked at $5 \mathrm{wt} \%$, by matrix preparation type.
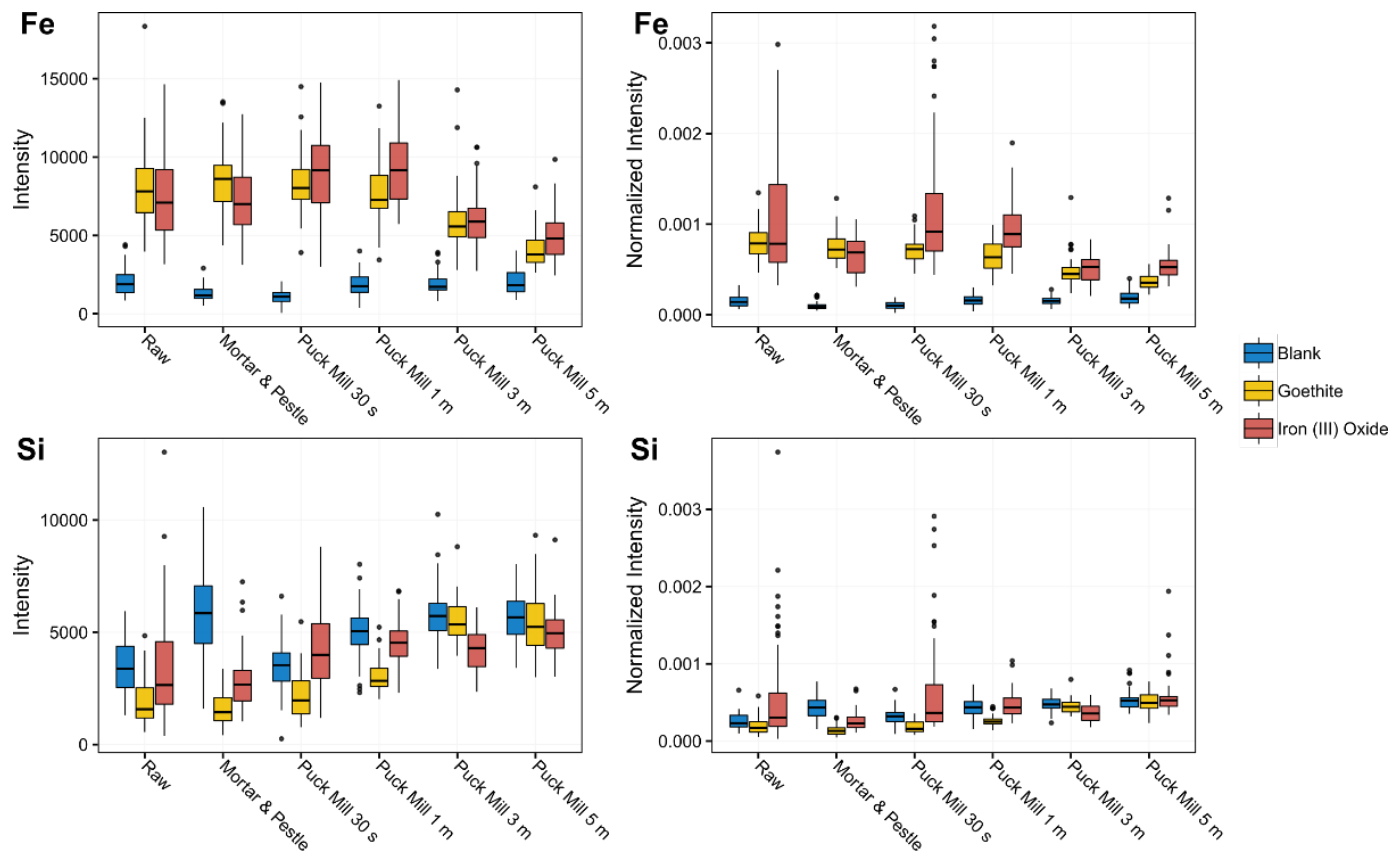

Table 1. Significant difference matrix of Fe intensities by pairwise t-tests. Goethite $(G)$ and iron (III) oxide ( $)$ with significant differences are indicated by * for $p$-values $<0.05$, ** for $p<0.01$, and $* * *$ for $p<0.001$.

\begin{tabular}{|l|l|c|c|c|c|}
\hline $\begin{array}{c}\text { Matrix } \\
\text { Preparation }\end{array}$ & \multicolumn{1}{|c|}{ Raw } & $\begin{array}{c}\text { Mortar and } \\
\text { Pestle }\end{array}$ & Puck Mill 30 s & $\begin{array}{c}\text { Puck Mill 1 } \\
\text { min }\end{array}$ & $\begin{array}{c}\text { Puck Mill } \\
3 \text { min }\end{array}$ \\
\hline Mortar and Pestle & NA & - & - & - & - \\
\hline Puck Mill 30 $\mathrm{s}$ & $\mathrm{I}^{* * *}$ & $\mathrm{I}^{* * *}$ & - & - & - \\
\hline Puck Mill 1 min & $\mathrm{I}^{* * *}$ & $\mathrm{G} * \mathrm{I}^{* * *}$ & $\mathrm{NA}$ & - & - \\
\hline Puck Mill 3 $\min$ & $\mathrm{G} * * *, \mathrm{I}^{* *}$ & $\mathrm{G} * * *, \mathrm{I}^{*}$ & $\mathrm{G} * * *, \mathrm{I}^{* * *}$ & $\mathrm{G} * * *, \mathrm{I}^{* * *}$ & - \\
\hline Puck Mill $5 \mathrm{~min}$ & $\mathrm{G} * * *, \mathrm{I}^{* * *}$ & $\mathrm{G} * * *, \mathrm{I}^{* * *}$ & $\mathrm{G} * * *, \mathrm{I}^{* * *}$ & $\mathrm{G} * * *, \mathrm{I}^{* * *}$ & $\mathrm{G} * * *, \mathrm{I}^{*}$ \\
\hline
\end{tabular}

Silicon intensities are typically minimal in raw and mortar and pestle matrices (Figure 6). As puck milling time increases, Si intensities tend to increase, regardless of spike material, until 3 minutes when intensities appear to level off. These trends are supported by pairwise significant differences up to the 3-minute puck milling period (Table 2). Silicon intensities increase the greatest for goethite compared with iron (III) oxide and blank OS. Normalized Si intensities show similar trends but with considerably greater variability.

Figure 7 assesses measurement precision for both $\mathrm{Fe}$ and $\mathrm{Si}$. The relative standard deviation (RSD) computed between the nine shots within one 
repetition (intra-RSD) is relatively stable for Fe between different matrix preparations. Goethite has slightly better precision than iron (III) oxide in raw and minimally processed matrices. Precision between the six repetition measurements (inter-RSD) for Fe is also greater for goethite in raw and minimally processed matrices. Whereas inter-RSDs are generally low for goethite across all matrix types, iron (III) oxide inter-RSD seems to decrease with increasing matrix processing.

Table 2. Significant difference matrix of Si intensities by pairwise t-tests. Goethite $(G)$, iron (III) oxide ( $($ ), and blank $(B)$ with significant differences are indicated by * for $p$-values $<0.05$, $* *$ for $p<0.01$, and $* * *$ for $p<0.001$.

\begin{tabular}{|c|c|c|c|c|c|}
\hline & Raw & $\begin{array}{l}\text { Mortar and } \\
\text { Pestle }\end{array}$ & Puck Mill $30 \mathrm{~s}$ & $\begin{array}{l}\text { Puck Mill } \\
1 \text { min }\end{array}$ & $\begin{array}{l}\text { Puck Mill } \\
3 \mathrm{~min}\end{array}$ \\
\hline Mortar and Pestle & $1 *, B * * *$ & - & - & - & - \\
\hline Puck Mill $30 \mathrm{~s}$ & $1 *$ & $\begin{array}{l}G * *, 1 * * *, \\
B * * *\end{array}$ & - & - & - \\
\hline Puck Mill 1 min & $\begin{array}{l}\mathrm{G} * * *, 1 * * \\
\mathrm{~B}^{* * *}\end{array}$ & $\begin{array}{l}G * * *, 1 * * * \\
B * *\end{array}$ & $G * * *, B * * *$ & - & - \\
\hline Puck Mill 3 min & $\begin{array}{l}G * * *, 1 *, \\
B * * *\end{array}$ & $\mathrm{G} * * *, 1 * * *$ & $G * * *, B^{* * *}$ & $G * * *, B * *$ & - \\
\hline Puck Mill 5 min & $\begin{array}{l}\mathrm{G} * * *, 1 * * *, \\
\mathrm{~B}^{* * *}\end{array}$ & $G * * *, 1 * * *$ & $\begin{array}{l}G * * *, I *, \\
B * * *\end{array}$ & $G * * *, B * *$ & $1^{*}$ \\
\hline
\end{tabular}

Figure 7. Relative standard deviations for Fe $(373.530 \mathrm{~nm})$ and Si $(288.234 \mathrm{~nm})$ emission intensities between individual shots within a repetition (intra-RSD) and between the six repetitions per sample (inter-RSD). Error bars are \pm 1 standard deviation.
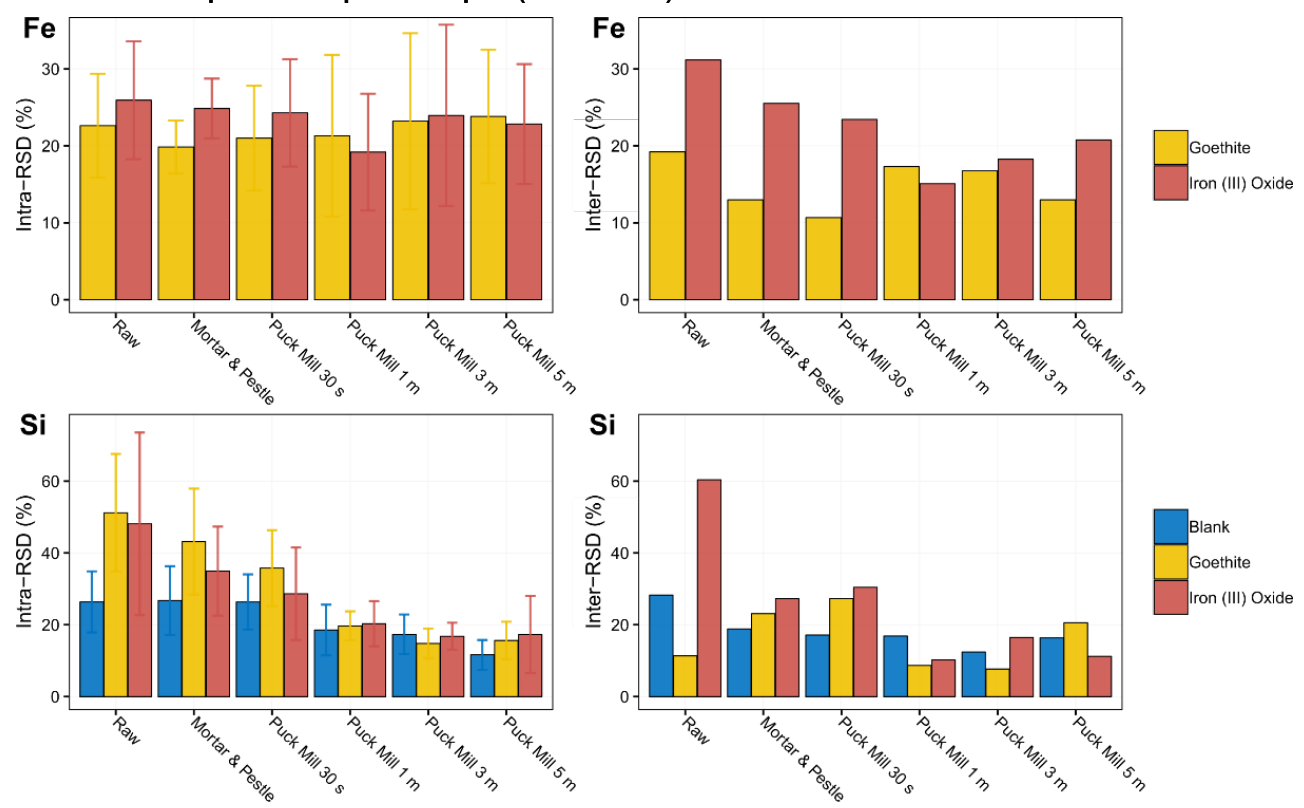
Silicon intra-RSDs are initially high for both iron spike materials in raw and minimally processed matrices but steadily decrease to about $20 \%$ with prolonged milling (Figure 7). Improved intra-RSD is also apparent in blanks but remains relatively good even in raw and minimally processed matrices. Silicon inter-RSDs also improved with increasing matrix processing.

We hypothesize that the observed trends in Fe and Si intensity and precision are the result of particle-size effects. To investigate functional trends, Figure 8 plots LIBS performance against median matrix particle size for both iron spikes. Visually, an increase in Fe intensity with increasing matrix particle size for both goethite and iron (III) oxide occurs up to a median matrix particle size of $32 \mu \mathrm{m}$, above which intensities remain relatively enhanced. Iron RSDs are roughly equivalent across tested matrix particle sizes and spike materials. Silicon intensity tends to decrease with increasing particle size, but this trend is most pronounced for the goethite spike, with intensity decreasing until a median matrix particle size of $103 \mu \mathrm{m}$. For both spike materials, Si RSD steadily increases with particle size across the studied median matrix particle sizes of 19 to $810 \mu \mathrm{m}$.

Figure 8. Fe $(373.530 \mathrm{~nm})$ and $\mathrm{Si}(288.234 \mathrm{~nm})$ intensity and precision as a function of median matrix particle size. The median particle sizes for the studied goethite and iron (III) oxide are 0.99 and $74 \mu \mathrm{m}$, respectively.
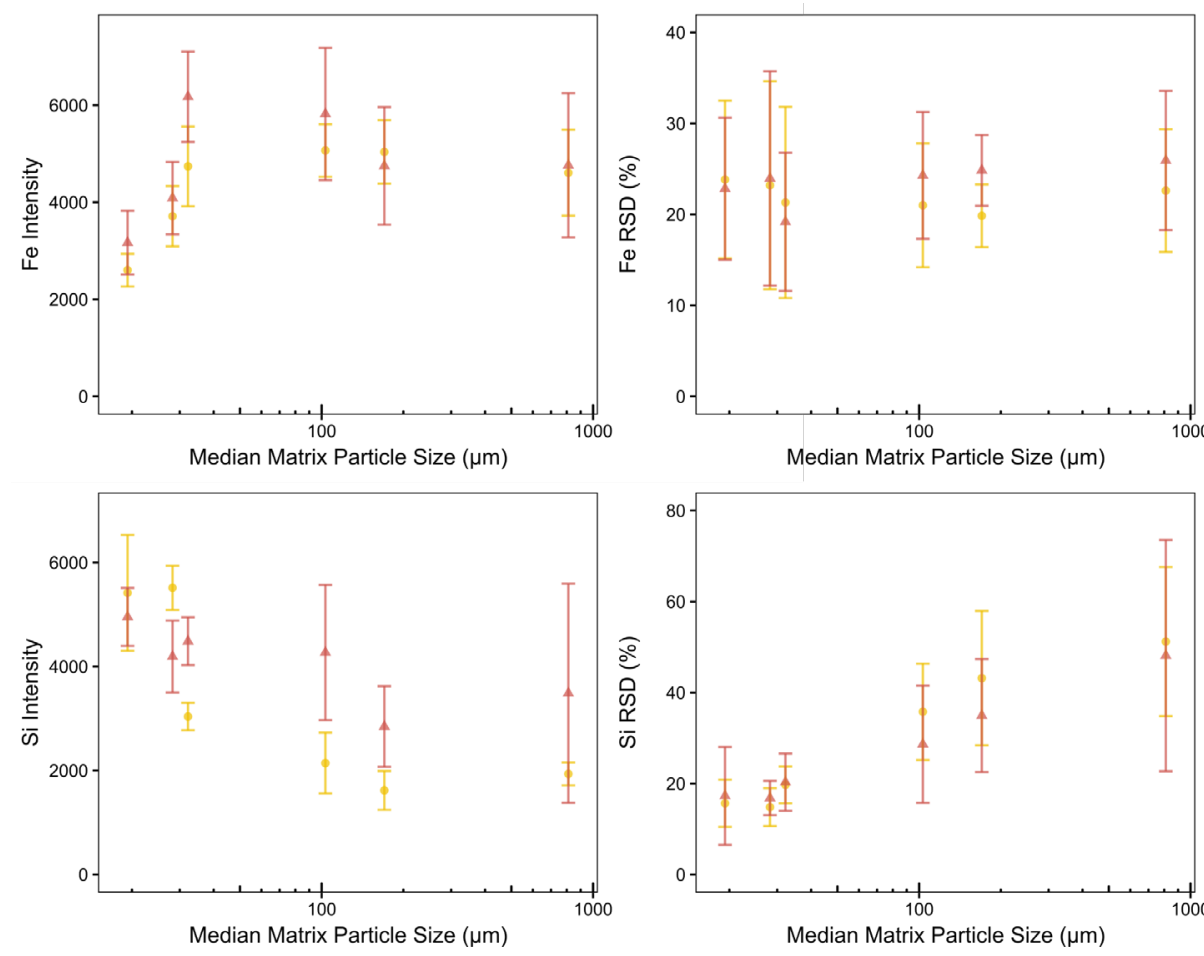
The positive relationship between matrix particle size and target intensity is consistent with Wisbrun et al. (1994), Eppler et al. (1996), and Krasniker et al. (2001). Whereas Wisbrun et al. (1994) attributed this effect to differences in surface concentration of the target, Krasniker et al. (2001) attributed it to differences in ablated crater size, with larger matrices having larger ablated volume. Our observed negative relationship between matrix particle size and Si intensity suggests that the effect is the result of surface concentration effects, and not ablated volume, in our study. The surface concentration effect is also apparent in visible inspection of the samples. Although the total weight of Fe per weight matrix remained the same for all samples ( $5 \mathrm{wt} \%$ ), the color of each sample dramatically lightened with increasing matrix processing for both spike materials (Figure 9). We hypothesize that, as matrix particle size decreased, the surface area of the matrix increased; and therefore, the surface concentration of Fe decreased. At the smallest matrix particle size, the Si intensity was greatest because the Fe particles were effectively diluted from the surface and had less of a masking effect on Si grains. The threshold for this effect seems to be about 32 to $100 \mu \mathrm{m}$, regardless of the target particle size, and is approximately equivalent to the spot size of the laser. Whereas Fe precision is largely unaffected by matrix or target particle size, Si precision decreased with increasing particle size, suggesting the greater surface concentration of $\mathrm{Fe}$ interfered with replicate measurements of the matrix, potentially due to masking. The observed particle-size dependence on LIBS may have relevance to the unequal sphere packing problem, optimizing the solution for reproducible surface concentration instead of maximum density.

Figure 9. Images of goethite (left) and iron (III) oxide (right) samples spiked to $5 \mathrm{wt} \%$. In both images, the matrix is raw on the left and increases in level of processing toward the right.
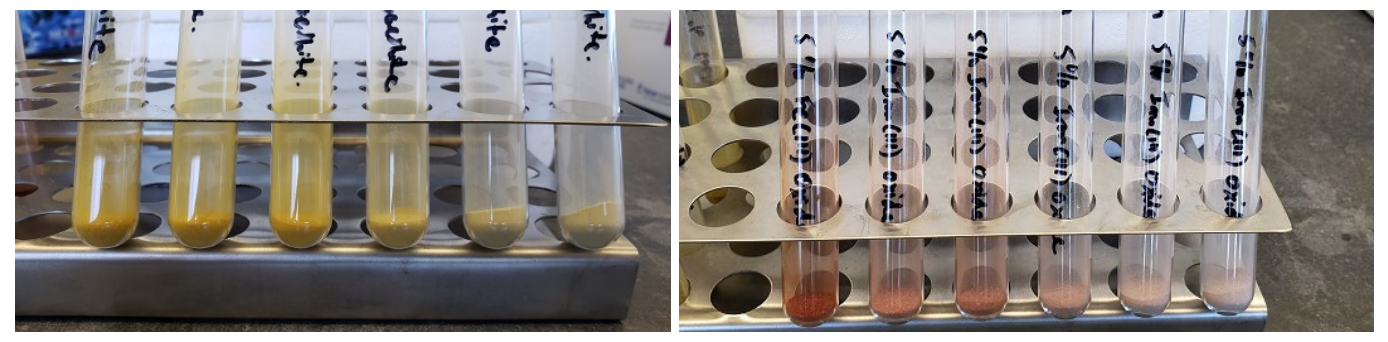

\subsection{Implications}

An overall approximately 50\% difference in target intensity between essentially powdered matrix and sand-sized matrix could have a significant impact when applying LIBS to soil samples. We observed this effect for particulate targets with median diameters of 1 and $74 \mu \mathrm{m}$, but it has also 
been observed for solution-spiked materials (Wisbrun et al. 1994; Krasniker et al. 2001). In conducting quantitative analysis of soils, it is imperative that the standards have the same matrix particle size as the unknowns. We expect matrices with very small particle sizes to have higher detection limits than matrices with larger particle sizes, with the exception of elements that compose the matrix itself, which have the opposite effect. However, matrix element precision is typically unacceptable for large $(>100 \mu \mathrm{m})$ matrix particle sizes. Overall, these results show that prior assumption of the particle size with which an element of interest associates is needed to inform the most appropriate sample preparation method.

Matrix particle size is one factor among others that complicates the analysis of soils by LIBS. Eppler et al. (1996) found metal speciation to control signal intensity for $\mathrm{Pb}$ and $\mathrm{Ba}$, with an overall effect of about $50 \%$, similar in magnitude to the particle-size effect found here. Wisbrun et al. (1994) showed that water content extinguished LIBS intensities at water contents greater than $5 \%$ and $25 \%$ for sand and soil, respectively, with quasi exponential decreases leading up to these thresholds. Combined, these factors require attention and control by analysts for reliable quantitative analysis of soils by LIBS. Nevertheless, some soil settings may be particularly amenable to in situ quantitative analysis (e.g., dry environments). 


\section{Conclusions}

This study found that matrix particle size affects both target and matrix element intensity and precision measurements significantly, by up to approximately 50\%. Spiked Fe intensity decreased with increasing matrix milling and decreasing matrix particle size. Conversely, the matrix element Si experienced increasing intensity with increasing matrix milling and decreasing matrix particle size. We attributed these changes in intensity to differences in surface concentration, and this effect is plainly visible in the studied samples when spiked with both of the studied Fe spike materials at 5 wt\%. Acceptable Fe precision (less than about 20\% RSD) was obtained for $1 \mu \mathrm{m}$ size Fe spikes in raw matrices but required further matrix preparation and particle-size reduction for the larger $74 \mu \mathrm{m}$ Fe spike. Acceptable precision for measurements of the matrix component Si required grinding in a puck mill to produce a matrix particle size less than $100 \mu \mathrm{m}$.

Overall, these results indicate that accurate LIBS measurements require the matching of particle sizes between standards and unknowns and that precise LIBS measurements require substantial particle-size reduction, for instance by puck milling the sample for at least 3 minutes. Practically, these steps increase the amount of processing that soil samples must undergo prior to quantitative analysis by LIBS and must occur ex situ. These additional processing steps, in addition to pellet pressing, reduce the appeal of LIBS for ex situ analysis when compared with standard elemental analyses such ICP-MS. Although LIBS has demonstrated great potential for in situ and long-standoff elemental analysis, the significant effects of matrix and target particle sizes on emission intensities present an additional obstacle to achieve quantitative in situ elemental analysis of soils. Lacking immediate solutions to the particle size, speciation, and moisture effects, in situ LIBS may find best application in qualitative and semiquantitative analysis of soils for purposes of contaminant screening or classifying soils by lithology, provenance, or disturbance. 


\section{References}

Alexander, D. R., and D. E. Poulain. 1996. Quantitative Analysis of the Detection Limits for Heavy-Metal-Contaminated Soils by Laser-Induced Breakdown Spectroscopy. Vicksburg, MS: U.S. Army Engineer Waterways Experiment Station.

Anzano, J. M., M. A. Villoria, A. Ruíz-Medina, and R. J. Lasheras. 2006. "Laser-Induced Breakdown Spectroscopy for Quantitative Spectrochemical Analysis of Geological Materials: Effects of the Matrix and Simultaneous Determination." Analytica Chimica Acta 575 (2): 230-235. https://doi.org/10.1016/i.aca.2006.05.077.

Cousin, A., P. Y. Meslin, R. C. Wiens, W. Rapin, N. Mangold, C. Fabre, O. Gasnault, O. Forni, R. Tokar, A. Ollila, S. Schröder, J. Lasue, S. Maurice, V. Sautter, H. Newsom, D. Vaniman, S. Le Mouélic, D. Dyar, G. Berger, D. Blaney, M. Nachon, G. Dromart, N. Lanza, B. Clark, S. Clegg, W. Goetz, J. Berger, B. Barraclough, and D. Delapp, MSL Science Team. 2015. "Compositions of Coarse and Fine Particles in Martian Soils at Gale: A Window into the Production of Soils." Icarus 249:2242. https://doi.org/10.1016/j.icarus.2014.04.052.

Eppler, A. S., D. A. Cremers, D. D. Hickmott, M. J. Ferris, and A. C. Koskelo. 1996. "Matrix Effects in the Detection of $\mathrm{Pb}$ and Ba in Soils Using Laser-Induced Breakdown Spectroscopy." Applied Spectroscopy 50 (9): 1175-1181.

Fortes, F. J., J. Moros, P. Lucena, L. M. Cabalin, and J. J. Laserna. 2013. "Laser-Induced Breakdown Spectroscopy." Analytical Chemistry 85 (2): 640-669. https://doi.org/10.1021/ac303220r.

Goueguel, C. L., A. Soumare, C. Nault, and J. Nault 2019. "Direct Determination of Soil Texture Using Laser-Induced Breakdown Spectroscopy and Multivariate Linear Regressions." Journal of Analytical Atomic Spectrometry 34:1588-1596. http://dx.doi.org/10.1039/C9JA00090A.

Harmon, R. S., R. E. Russo, and R. R. Hark. 2013. “Applications of Laser-Induced Breakdown Spectroscopy for Geochemical and Environmental Analysis: A Comprehensive Review." Spectrochimica Acta Part B: Atomic Spectroscopy 87:11-26. https://doi.org/10.1016/j.sab.2013.05.017.

Kim, G., J. Kwak, K.-R. Kim, H. Lee, K. Kyoung-Woong, H. Yang, and K. Park. 2013. "Rapid Detection of Soils Contaminated with Heavy Metals and Oils by Laser Induced Breakdown Spectroscopy (LIBS).” Journal of Hazardous Materials 263 (2): 754-76o. https://doi.org/10.1016/i.jhazmat.2013.10.041.

Kramida, A., K. Olsen, and Y. Ralchenko. 2019. NIST LIBS Database, National Institute of Standards and Technology. Accessed 13 September 2019. https://physics.nist.gov/PhysRefData/ASD/LIBS/libs-form.html.

Krasniker, R., V. Bulatov, and I. Schechter. 2001. "Study of Matrix Effects in Laser Plasma Spectroscopy by Shock Wave Propagation." Spectrochimica Acta Part B: Atomic Spectroscopy 56 (6): 609-618. https://doi.org/10.1016/S05848547(01)00194-X. 
Lopez-Moreno, C., S. Palanco, J. J. Laserna, F. DeLucia, A. W. Miziolek, J. Rose, R. A., Walters, and A. I. Whitehouse. 2006. "Test of a Stand-Off Laser-Induced Breakdown Spectroscopy Sensor for the Detection of Explosive Residues on Solid Surfaces." Journal of Analytical Atomic Spectrometry 21 (1): 55-60. https://doi.org/10.1039/B508055J.

R Core Team. 2019. R: A Language and Environment for Statistical Computing. Vienna, Austria: R Foundation for Statistical Computing. https://www.R-project.org/.

Sabsabi, M., R. Héon, and L. St-Onge. 2005. "Critical Evaluation of Gated CCD Detectors for Laser-Induced Breakdown Spectroscopy Analysis.” Spectrochimica Acta Part B: Atomic Spectroscopy 6o (7-9): 1211-1216.

https://doi.org/10.1016/i.sab.2005.05.030.

Tessier, A., P. G. C. Campbell, and M. Bisson. 1979. "Sequential Extraction Procedure for the Speciation of Particulate Trace Metals." Analytical Chemistry 51 (7): 844-851.

Villas-Boas, P. R., R. A. Romano, M. A. de Menezes Franco, E. C. Ferreira, E. J. Ferreira, S. Crestana, and D. M. B. Pereira Milori. 2016. "Laser-Induced Breakdown Spectroscopy to Determine Soil Texture: A Fast Analytical Technique." Geoderma 263: 195-202. https://doi.org/10.1016/j.geoderma.2015.09.018.

Wisbrun, R., I. Schechter, R. Niessner, H. Schröder, and K. L. Kompa. 1994. "Detector for Trace Elemental Analysis of Solid Environmental Samples by Laser Plasma Spectroscopy.” Analytical Chemistry 66 (18): 2964-2975. 


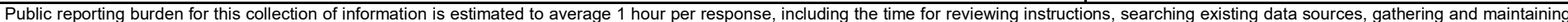

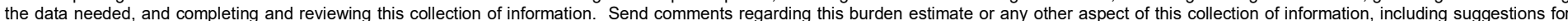

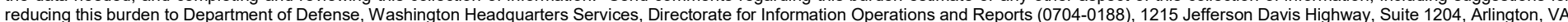

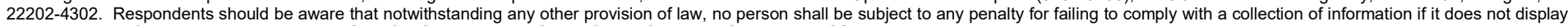
a currently valid OMB control number. PLEASE DO NOT RETURN YOUR FORM TO THE ABOVE ADDRESS.
1. REPORT DATE (DD-MM-YYYY)
January 2020

\section{TITLE AND SUBTITLE}

Matrix and Target Particle-Size Effects on LIBS Analysis of Soils
3. DATES COVERED (From - To) FY19

5a. CONTRACT NUMBER

\section{5b. GRANT NUMBER}

5c. PROGRAM ELEMENT NUMBER

06037348

\section{AUTHOR(S)}

Samuel A. Beal, Ashley M. Mossell, and Jay L. Clausen

5d. PROJECT NUMBER

T15

5e. TASK NUMBER

5f. WORK UNIT NUMBER

\section{PERFORMING ORGANIZATION NAME(S) AND ADDRESS(ES)}

U.S. Army Engineer Research and Development Center (ERDC)

Cold Regions Research and Engineering Laboratory (CRREL)

8. PERFORMING ORGANIZATION REPORT

NUMBER

ERDC/CRREL TR-20-1

72 Lyme Road

Hanover, NH 03755-1290

9. SPONSORING / MONITORING AGENCY NAME(S) AND ADDRESS(ES)

Headquarters, U.S. Army Corps of Engineers

Washington, DC 20314-1000

10. SPONSOR/MONITOR'S ACRONYM(S)

USACE

11. SPONSOR/MONITOR'S REPORT NUMBER(S)

\section{DISTRIBUTION / AVAILABILITY STATEMENT}

Approved for public release; distribution is unlimited.

\section{SUPPLEMENTARY NOTES}

\section{ABSTRACT}

Laser-induced breakdown spectroscopy (LIBS) is a rapid, low-cost analytical method with potential applications in quantitative analysis of soils for major and trace elements. Here we examined the effects of matrix and target particle sizes on measurements of soil composition by LIBS. The experimental approach involved milling a clean sand matrix to six different particle sizes (medians: 19 to $810 \mu \mathrm{m})$ and spiking each with two different iron (Fe) minerals (medians: 1 and $74 \mu \mathrm{m}$ ) to a constant concentration of $5 \mathrm{wt} \%$. The LIBS intensity of $\mathrm{Fe}$ emission lines decreased by $50 \%$ with increasing matrix processing and decreasing matrix particle size, regardless of spike. Conversely, emission lines of the matrix element silicon $(\mathrm{Si})$ increased with decreasing matrix particle size. We hypothesized that this intensity effect was a result of changing surface concentrations, which was also apparent under visual inspection of the samples. Precision was acceptable for the $1 \mu \mathrm{m} \mathrm{Fe}$ spike in all matrices but required further puck milling and particle-size reduction for the larger Fe spike and for determining Si content in both spikes and blanks. These results highlight the importance of matching matrix texture between standards and unknowns and of reducing particle size for quantitative LIBS analysis of soil.

\section{SUBJECT TERMS}

Contaminants, grain size, Laser-induced breakdown spectroscopy, metals, quantitative analysis, soil heterogeneity, Soils--Testing, standoff detection, Trace elements

\section{SECURITY CLASSIFICATION OF:}

\section{a. REPORT}

Unclassified

\section{b. ABSTRACT}

Unclassified

\section{c. THIS PAGE}

Unclassified
17. LIMITATION OF ABSTRACT
18. NUMBER OF PAGES

27 19a. NAME OF RESPONSIBLE PERSON

19b. TELEPHONE NUMBER (include area code) 